\title{
Long Term Oxidation of Model and Engineering TiAl Alloys
}

\author{
Ivan E. Locci ${ }^{1}$, Michael P. Brady ${ }^{2}$, James L. Smialek ${ }^{1}$ \\ ${ }^{1}$ NASA-Glenn Research Center, Cleveland, OH 44135, Ivan.E.Locci@ grc.nasa.gov \\ ${ }^{2}$ Oak Ridge National Laboratory, Oak Ridge, Tennessee 37831
}

\section{ABSTRACT}

The purpose of this research was to characterize the oxidation behavior of several model (TiAl, TiAl-Nb, TiAl-Cr, TiAl-Cr-Nb) and engineering alloys (XD, K5, Alloy 7, WMS) after long-term isothermal exposure $(\sim 7000 \mathrm{~h})$ at $704^{\circ} \mathrm{C}$, and after shorter time exposure $(\sim 1000 \mathrm{~h})$ at $800^{\circ} \mathrm{C}$ in air. High-resolution field emission and microprobe scanning electron microscopy were used to characterize the scales formed on these alloys. Similarities and differences observed in the scales are correlated with the various ternary and quaternary microalloying additions.

\section{INTRODUCTION}

Titanium aluminides (TiAl) are of great interest for intermediate-temperature $\left(600^{\circ} \mathrm{C}-850^{\circ} \mathrm{C}\right)$ aerospace, automotive, and power generation applications because they offer significant weight savings compared to today's nickel-based alloys. TiAl alloys are being investigated for low-pressure turbine (LPT) blade applications, exhaust nozzle components and compressor cases in advanced subsonic and supersonic engines [1-2], and exhaust valves in automobiles [2-4]. Significant progress has been made in understanding the fundamental aspects of the oxidation behavior of binary TiAl alloys [5-12]. However, most of this work has concentrated on shorter term $(<1000$ hours $)$, higher temperature $\left(900^{\circ} \mathrm{C}-1000^{\circ} \mathrm{C}\right)$ exposures. Much less data is available in the literature regarding the oxidation behavior of the quaternary and higher order engineering alloys under the long term, low temperature conditions likely to be encountered in near term structural applications $[5-6,11,13]$. The present investigation was undertaken to characterize the long-term oxidation behavior of various model and advanced engineering titanium aluminides at $704^{\circ} \mathrm{C}$ in air. Some engineering alloys were also exposed to $800^{\circ} \mathrm{C}$ in air for $1000 \mathrm{~h}$. Of particular interest for this study was the formation of nitrides, which have been linked to disruption of alumina scale formation in air [12,14], and the formation of brittle oxygen- and titanium- enriched, aluminum-depleted phase(s) at the metal scale interface, termed by various researchers as Z, X or NCP phase (new cubic phase) [14-18].

\section{EXPERIMENTAL PROCEDURES}

The alloys included in this investigation are listed in Table 1. All compositions presented in the paper are reported in atomic percent. Alloys were cast, hot isostatically pressed and heat treated to produce a duplex microstructure of $\gamma$-grains and $\alpha_{2}+\gamma$ lamellae. Several alloys were isothermally exposed to $704^{\circ} \mathrm{C}$ for 7000 hours and $800^{\circ} \mathrm{C}$ for 1000 hours in static air. All samples had a 600 -grit finish. Back-scattered electron (BSE) images and elemental maps of polished cross-sections were obtained by electron probe microanalysis (EPMA) equipped with a wavelength dispersive $x$-ray spectrometry (WDS) using pure element standards for $\mathrm{Ti}, \mathrm{Al}, \mathrm{Cr}, \mathrm{Nb}$, and a pure $\mathrm{MgO}$ standard for $\mathrm{O}$. A high-resolution field emission electron microscope (FESEM) equipped with BSE and low angle secondary electron (SE) detectors and an energy dispersive x-ray spectrometer (EDX) was used to resolve and analyze the fine multiple layers observed in the metal/scale interface formed in these alloys. Total weight gain was measured before and after exposure using an analytical balance. The scale thickness was measured at three different locations in regions that were not in contact with the supporting alumina boat.

\section{Results and Discussion}

\section{Oxidation at $704^{\circ} \mathrm{C}-7000 \mathrm{~h}-$ in Air}

Typical alloy compositions, the specific weight changes and the total scale thickness measured for each alloy after exposure to $704^{\circ} \mathrm{C}$ for $7000 \mathrm{~h}$ in air are included in Table 1 . The weight gain results are presented in Fig. 1. The binary TiAl alloy is the only one where the scale was not adherent and tended to spall-off. The TiAl-2Cr alloy showed significant weight gain, the thickest scale of all the alloys studied, and was the only alloy that reacted with the supporting alumina boat during the exposure treatment. Therefore, the weight gain values for TiAl and TiAl-2Cr obtained may be inaccurate. The presence of $\mathrm{Nb}$ as a ternary or quaternary addition was extremely beneficial, minimizing the weight gain 
even when $\mathrm{Cr}$ was present in the alloy. A phosphoric acid surface treatment [19] on the Ti48Al-2Cr-2Nb alloy had a pronounced beneficial effect resulting in a further reduction in the weight gain and scale thickening. The advanced engineering alloys, K5, XD-TiAl, Alloy 7 and WMS showed the smallest weight gain. A description of the complex scales that formed in these alloys during the exposure follows.

Table I. Compositions, weight gain, and scale thickness for model and engineering TiAl alloys exposed to $700^{\circ} \mathrm{C}$ for 7000 hours in static air

\begin{tabular}{|c|c|c|c|c|c|c|c|c|c|}
\hline Alloy $/$ & $\mathbf{A l}$ & $\mathrm{Ti}$ & $\mathrm{Cr}$ & $\mathrm{Nb}$ & w & Mo & $\mathbf{M n}$ & $\begin{array}{c}\text { Wt. } \\
\text { Change/area } \\
\left(\mathrm{mg}^{2} / \mathrm{cm}^{2}\right)\end{array}$ & $\begin{array}{c}\text { Scale }^{2} \\
\text { Thickness } \\
(\mu \mathrm{m})\end{array}$ \\
\hline $\mathrm{TiAl}^{3}$ & 47.31 & 52.69 & - & - & - & - & - & $428^{1}$ & 20 \\
\hline TiAl-2Crr ${ }^{4}$ & 46.58 & 51.43 & 1.99 & - & - & - & - & $10.29^{1}$ & 150 \\
\hline TiAl-2Nb & 47.67 & 50.35 & - & 1.98 & - & - & - & $1.43^{1}$ & 12 \\
\hline TiAl-2Cr-2Nb & 48.19 & 47.95 & 1.94 & 1.92 & - & - & - & $2.04^{1}$ & 15 \\
\hline $\begin{array}{l}\text { TiAl-2Cr-2Nb } \\
+ \text { + Surf. Treat. }\end{array}$ & 48.19 & 47.95 & 1.94 & 1.92 & - & - & - & $0.57^{1}$ & 6 \\
\hline K5 & 46.5 & 47.2 & 2 & 3 & 0.2 & - & - & 1.1 & 6 \\
\hline Alloy 7 & 46 & 48 & - & 5 & 1 & - & - & $0.41^{1}$ & 5 \\
\hline XD-TiAl & 47 & 51 & - & 2 & - & - & 2 & 0.86 & 9 \\
\hline WMS & 47 & 49 & - & 2 & 0.5 & 0.5 & 1 & $0.61^{\prime}$ & 4 \\
\hline
\end{tabular}

${ }^{1}$ Average of 2 samples; ${ }^{2}$ Average of 3 regions; ${ }^{3}$ Including spall

${ }^{4}$ Reacted with $\mathrm{Al}_{2} \mathrm{O}_{3}$ boat

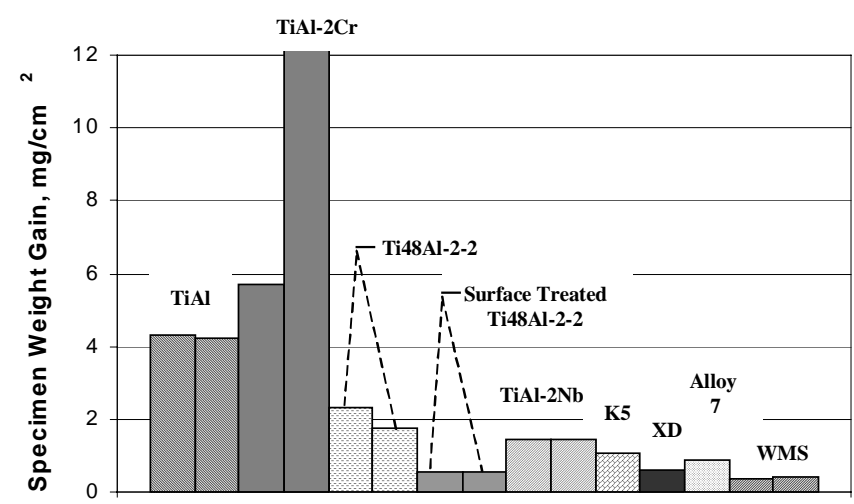

Figure 1. Specimen weight gain for model and advanced $\gamma$-TiAl alloys after isothermal exposure to $704^{\circ} \mathrm{C}$ for $7000 \mathrm{~h}$ in air.

Model Alloys: Ti-48Al -- A typical cross section of the scale $(20 \mu \mathrm{m}$ thick) formed and a series of microprobe elemental maps, which show the distribution of $\mathrm{Ti}, \mathrm{Al}, \mathrm{N}$, and $\mathrm{O}$ in the different regions of the scale, are presented in Figure 2. The scale has fractured in the middle of the intermixed layer composed of $\mathrm{TiO}_{2}$ and some $\mathrm{Al}_{2} \mathrm{O}_{3}$. Typically rutile $\left(\mathrm{TiO}_{2}\right)$ needles/platelets are observed on the scale surface, followed by a discontinuous $\mathrm{Al}_{2} \mathrm{O}_{3}$ layer and an intermixed $\mathrm{Al}_{2} \mathrm{O}_{3} / \mathrm{TiO}_{2}$ region. Two other layers at the subscale, next to the metal, are clearly visible. The first layer, next to the metal is very rich in $\mathrm{Al}$; microprobe analyses indicate that this rich phase has chemistry close to $\mathrm{TiAl}_{2}$; the second layer is rich in $\mathrm{Ti}$ and $\mathrm{N}$ and $\mathrm{Al}$. An Al-enriched zone below the scale has also been reported for $\mathrm{Nb}$ and Mo-containing alloys $[5,20]$. A Microprobe linescan that reflects the changes in chemistry for the multiple layers that formed at the metal/scale sub-surface is included in Fig. 2. It should be noted that such extensive nitride formation and Al enrichment at the metal/scale interface does not appear to occur under shorter term, higher temperature exposure conditions. For example, Dettenwanger et al. [14] report Al depletion and Z/X phase formation at the metal/scale interface for oxidation of Ti-50Al at $900^{\circ} \mathrm{C}$ in air, which suggests a change in oxidation mechanism between $900^{\circ} \mathrm{C}$ and $700^{\circ} \mathrm{C}$ for binary $\gamma$-TiAl alloys. On the other hand, Magnan et al., on nitridation of TiAl at $1000^{\circ} \mathrm{C}$ reported the formation of a surface nitride scale and an Al-enriched subscale [21].

TiAl-2Cr -- Figure 3 (a) shows an image and corresponding maps for the TiAl-2Cr sample after the $7000 \mathrm{hr}$ exposure. Large blocky rutile crystals (30-40 $\mu \mathrm{m}$ thick) are observed on the outer part of the scale followed by a large area of porosity, probably left by the preferential outward growth of $\mathrm{TiO}_{2}$. A discrete $\mathrm{Al}_{2} \mathrm{O}_{3}$ layer is detected, followed by finer porosity in a thin $\mathrm{TiO}_{2}$ region. An extended region of alternating layers of $\mathrm{Al}_{2} \mathrm{O}_{3} /$ $\mathrm{TiO}_{2}$ is beneath that layer. The appearance of this layered intermixed region is very atypical compared to the binary TiAl and other TiAl alloys, where a spottier intermixed region is generally observed. This intermixed region is followed by a bright Al-depleted (Ti-rich)/O-rich layer right at the metal/scale interface; its average microprobe chemistry is $58 \mathrm{Ti}, 28 \mathrm{Al}, 10.8 \mathrm{O}$ and $2.3 \mathrm{Cr}$. This layer is speculated to be the Z/X phase described in [12-14]. No N-enrichment was detected at the subscale, although Haanappel et al. [8,22] reported the presence of Ti-nitrides after $150 \mathrm{~h}$ at $700^{\circ} \mathrm{C}$ in Ti48Al-2Cr. Higher FE-SEM magnification images, shown in Figure 3 (b), provide some fine details of the scale/metal interface. Alternating vertical channels (pipes) of $\mathrm{Al}_{2} \mathrm{O}_{3} / \mathrm{TiO}_{2}$ connect the bright Ti-rich/O-rich layer to the scale. A few $\mathrm{Cr}$ rich particles are also present in the channeled region. This channeled region morphology may be a form of internal oxidation and is reminiscent of that reported by Doychak et al. [23] for the accelerated oxidation of $\mathrm{NbAl}_{3}$ and Brady et al. [24] for the rapid oxidation of a Ti modified $\sigma-\mathrm{Nb}_{2} \mathrm{Al}$ alloy. Observation of the intermixed $\mathrm{Al}_{2} \mathrm{O}_{3} / \mathrm{TiO}_{2}$ region suggests that the channel morphology occurred throughout the course of oxidation. The detrimental effects of small $\mathrm{Cr}$ additions on the oxidation of TiAl have generally been postulated to result from doping effects of $\mathrm{Cr}$ on $\mathrm{TiO}_{2}$ growth rate [25]. However, the present results suggest that $\mathrm{Cr}$ may also promote this channel form 


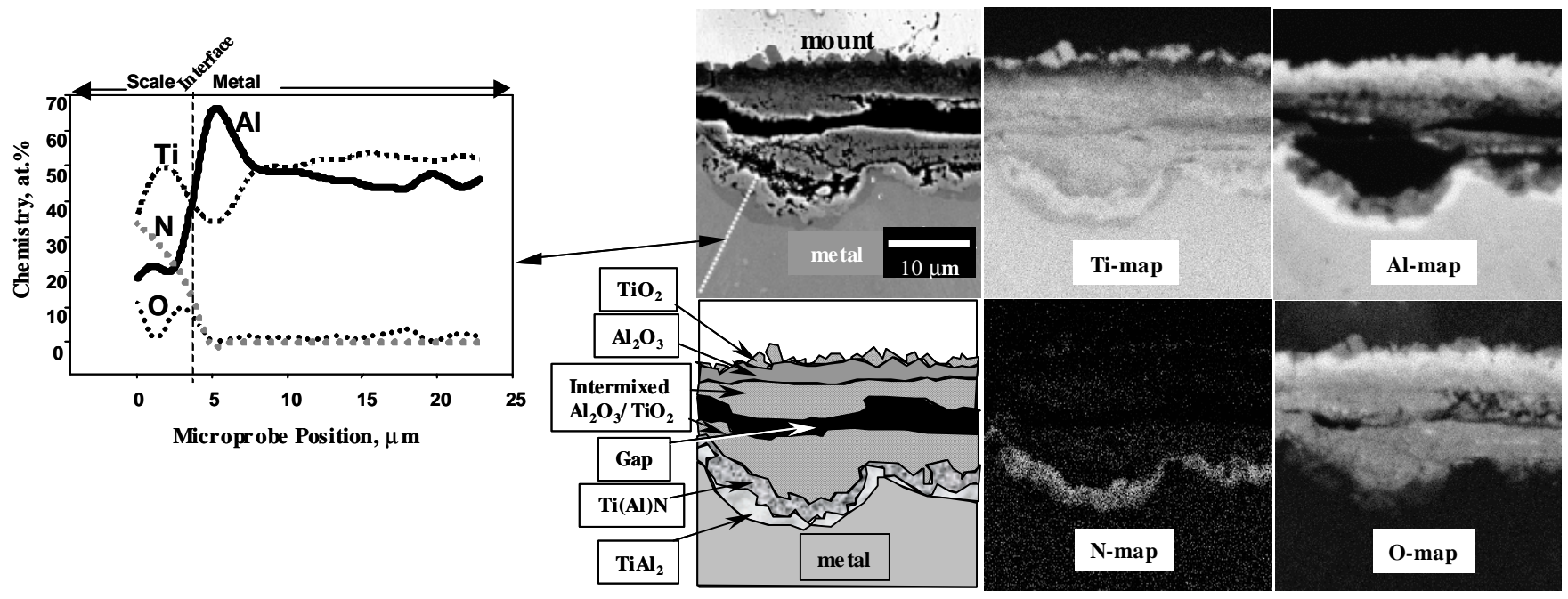

Figure 2. Typical microstructure, microprobe elemental maps and linescans observed in a binary $\gamma$-TiAl alloy after exposure to $704^{\circ} \mathrm{C}$ for $7000 \mathrm{hr}$ in air.
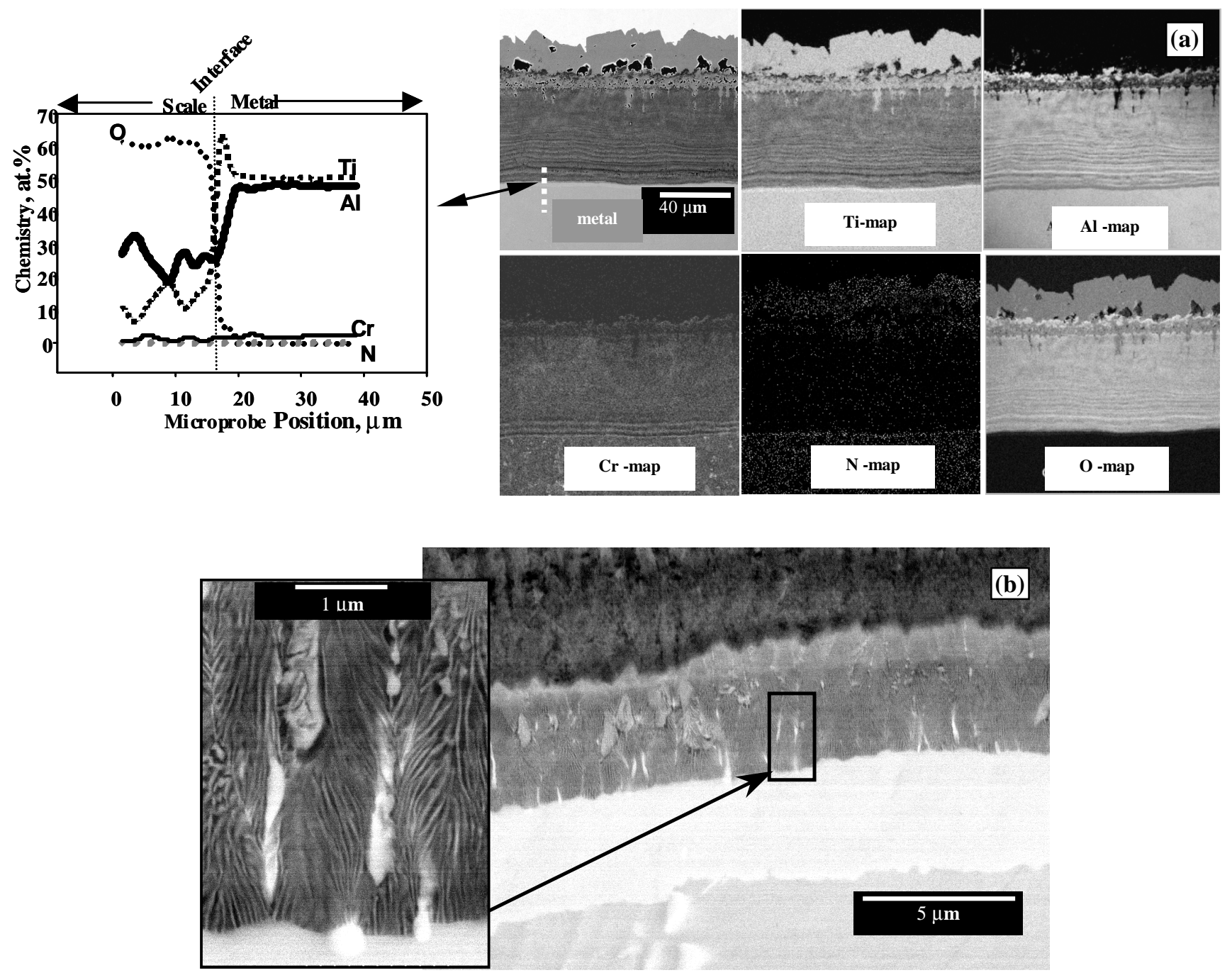

Figure 3. (a) Typical microstructure, microprobe elemental maps and linescans observed in a TiAl-2Cr alloy after exposure to $704^{\circ} \mathrm{C}$ for $7000 \mathrm{hr}$ in air. (b) Higher magnification of the scale/metal interface showing the alternating vertical $\mathrm{Al}_{2} \mathrm{O}_{3} / \mathrm{TiO}_{2}$ channels that connect the Ti-Al-O rich layer to the scale. 
of internal oxidation, possibly by increasing oxygen solubility in the alloy, although it is difficult to distinguish whether the channel morphology is a consequence of the more rapid oxidation with $\mathrm{Cr}$ additions or the cause of it. It is somewhat consistent with the mechanism forwarded by Shida and Anada [25], which interpreted beneficial or detrimental effects of ternary additives to TiAl in terms of oxygen solubility and internal/external oxidation and its effect on alumina morphology.

TiAl-2Nb -- A nearly continuous $\mathrm{Al}_{2} \mathrm{O}_{3}$ scale ( 2 $\mu \mathrm{m}$ thick), containing a few spots of $\mathrm{TiO}_{2}$ was observed near the gas/scale interface with a few discontinuous $\mathrm{TiO}_{2}$ needles at the surface. The remainder of the scale as observed in the other alloys consisted of the intermixed $\mathrm{TiO}_{2} / \mathrm{Al}_{2} \mathrm{O}_{3}$ richer in $\mathrm{TiO}_{2}$. A thin discontinuous Ti(Al)$\mathrm{N}$ rich layer was formed at the metal/scale interface. No Al-enriched or depleted layer was distinguished.

Ti48Al-2Cr-2Nb -- Detailed description of the scale formed in this system has been reported earlier $[5,6]$. Typically, the scale consisted of an outer layer of $\mathrm{TiO}_{2}$ and an inner intermixed layer of $\mathrm{Al}_{2} \mathrm{O}_{3} / \mathrm{TiO}_{2}$. Observations after $6000 \mathrm{~h}$ revealed that a nearly continuous layer of $\mathrm{Al}_{2} \mathrm{O}_{3}$ separated these regions. $A$ continuous $\mathrm{Ti}(\mathrm{Al})-\mathrm{N}$ rich layer nearly $1 \mu \mathrm{m}$ thick was formed at the alloy/scale interface. Discontinuous $\mathrm{Cr} / \mathrm{Nb}-$ enriched phases decorated this layer. These results are consistent with results reported by Sunderkotter for the oxidation of Ti-48Al-2Cr-2Nb after exposure for $150 \mathrm{~h}$ at $800^{\circ} \mathrm{C}$ [26]. The alloy ahead of this layer was significantly depleted in $\mathrm{Ti}$ and enriched in Al by approximately 10 at.\% each. Based on the composition analyses, the $\mathrm{N}$ containing layer consisted of the TiN phase (with a minor amount of $\mathrm{Al}$ ), and the Tidepleted/Al-enriched layer consisted of the $\mathrm{TiAl}_{2}$ phase.

Engineering Alloys: $\mathrm{XD}-\mathrm{TiAl}$-- The scale formed in the advanced engineering alloys is more complex than that observed on the model alloys with regards to the structure at the metal/scale interface. Figure 4 shows a typical cross section of the scale ( 9 $\mu \mathrm{m}$ thick) formed on the XD-TiAl alloy. A few $\mathrm{TiO}_{2}$ whiskers are observed at the surface followed by a nearly continuous $\mathrm{Al}_{2} \mathrm{O}_{3}$ layer. Next is the typical intermixed $\mathrm{Al}_{2} \mathrm{O}_{3} / \mathrm{TiO}_{2}$ layer. The metal/scale interface consists of two fairly well defined layers. The one next to the matrix (white contrast) is very rich in $\mathrm{Mn}$ and also enriched in $\mathrm{Nb}$; typical microprobe chemistry is $31.6 \mathrm{Ti}, 34.5 \mathrm{Al}, 5.4 \mathrm{Nb}$, $15.3 \mathrm{Mn}, 6.5 \mathrm{O}, 6.8 \mathrm{~N}$. The layer next to the intermixed region (gray contrast) is Ti and $\mathrm{N}$-enriched; typical chemistry is $37.7 \mathrm{Ti}, 17 \mathrm{Al}, 2.3 \mathrm{Nb}, 4 \mathrm{Mn}, 22 \mathrm{~N}, 17 \mathrm{O}$. Large $\mathrm{TiB}_{2}$ particles can be observed in the matrix. $\mathrm{A}$ FE-SEM line scan showing the chemistry variation across the metal scale interface is included in Fig. 4.

Alloy K5 -- Figure 5 shows a typical cross section of the scale ( $6 \mu \mathrm{m}$ thick) formed on alloy $\mathrm{K} 5$. Similarly to the XD-alloy, a few $\mathrm{TiO}_{2}$ whiskers are observed at the surface followed by a nearly continuous $\mathrm{Al}_{2} \mathrm{O}_{3}$ layer. The typical intermixed $\mathrm{Al}_{2} \mathrm{O}_{3} / \mathrm{TiO}_{2}$ layer follows. The metal/scale interface is more complex. Higher magnification observations revealed at least two main layers. The layer next to the metal (white contrast) is $\mathrm{Cr}$ and $\mathrm{Nb}$ enriched. $\mathrm{A} \mathrm{Ti}$ and $\mathrm{N}$-enriched layer (gray contrast), interrupted by pockets of $\mathrm{Al}_{2} \mathrm{O}_{3}$, is observed next to the intermixed region. Microprobe chemistry for both layers are, $31.3 \mathrm{Ti}, 30 \mathrm{Al}, 4.2 \mathrm{Nb}, 3.1 \mathrm{Cr}, 0.2 \mathrm{~W}$, $6.9 \mathrm{O}, 23.9 \mathrm{~N}$ and $37.7 \mathrm{Ti}, 5.3 \mathrm{Al}, 1 \mathrm{Nb}, 2.1 \mathrm{Cr}, 51.7 \mathrm{~N}, 0.3 \mathrm{~W}$, respectively. Since these layers are much less than 1 micron thick, chemical contribution from neighboring regions is occurring. Also in certain areas (not shown in Fig. 5), a discontinuous Al-enriched layer was observed next to the metal. Typical microprobe chemical analysis for the matrix is $47.9 \mathrm{Ti}, 47.4 \mathrm{Al}, 2.6 \mathrm{Nb}, 1.9 \mathrm{Cr}, 0.16 \mathrm{~W}$, which is comparable to the bulk alloy composition.

Alloy 7 -- A typical cross section of the scale ( $5 \mu \mathrm{m}$ thick) formed on the Alloy 7 after exposure is presented in Fig. 6. This alloy, which contains 5 at. $\%$ of $\mathrm{Nb}$, has very few $\mathrm{TiO}_{2}$ whiskers at the surface and an almost continuous $\mathrm{Al}_{2} \mathrm{O}_{3}$ layer follows beneath. Next is an intermixed $\mathrm{Al}_{2} \mathrm{O}_{3} / \mathrm{TiO}_{2}$ with apparently more $\mathrm{Al}_{2} \mathrm{O}_{3}$ compared to other alloys. A difficult to resolve thin Ti-rich nitride layer followed by a Nb-enriched region was observed. No Al-enriched or depleted layer at the metal/scale interface was detected.

\section{Oxidation at $800^{\circ} \mathrm{C}-1000 \mathrm{hr}-\mathrm{in}$ Air}

Ti48Al-2Cr-2Nb -- The appearance of the scale $\left(\sim 12 \mu \mathrm{m}\right.$ thick) formed on the Ti-48-2Cr-2Nb after the $800^{\circ} \mathrm{C}$ exposure is very similar to the long-term exposure at $704^{\circ} \mathrm{C}$. Main differences occurred at the interface where multiple layers have formed at the metal/scale interface. A high magnification FE-SEM image, shown in Figure 7, reveals four main layers, beyond the intermixed region. First, an alumina region containing small discrete particles is observed beneath the intermixed region. This is followed by a Ti-N enriched region (white), a Nb-enriched region (grayish), and lastly (slightly darker) an Al-enriched region next to metal.

Alloy $\mathrm{K} 5$ - The scale thickness formed on alloy $\mathrm{K} 5$ was approximately $\sim 14 \mu \mathrm{m}$ thick with features similar to the sample exposed to $704^{\circ} \mathrm{C}$ (Fig.5). Two well-defined bright regions, both enriched in $\mathrm{Nb}$, were observed at the metal/scale interface (Fig.8 (a)). Oxygen was only detected in the Nb-enriched bright region next to 
intermixed region. A third region, enriched in $\mathrm{Ti}$ and $\mathrm{N}$, separates the two $\mathrm{Nb}$-enriched regions. No Alenriched layer at the metal/scale interface was detected in the regions investigated.

Alloy 7 -- Alloy 7 developed a $6 \mu \mathrm{m}$ thick scale during the $800^{\circ} \mathrm{C}$ exposure. Alumina nodules lightly coated with $\mathrm{TiO}_{2}$ were observed at the surface. The nodules seem to be connected by a thin but continuous $\mathrm{Al}_{2} \mathrm{O}_{3}$ layer above the intermixed layer. Figure 8 (b) shows a high magnification of the metal/scale interface. A Nbenriched layer next to the metal precede a brighter and thick Ti-N enriched region which is interrupted by pockets of $\mathrm{Al}_{2} \mathrm{O}_{3}$ ahead of the intermixed region. W-rich particles have concentrated near the metal/scale interface.

\section{Conclusions}

This study shows the complex nature of the scale that can form on TiAl alloys during high temperature exposure in air. None of the alloys form a true continuous alumina layer and nearly all formed nitrogen enriched zones at the alloy/scale interface. Alloy 7 and alloy $\mathrm{K} 5$ show excellent oxidation resistance at 704 and $800^{\circ} \mathrm{C}$. With the exception of binary TiAl and TiAl-2Cr, all the TiAl alloys exhibit good long-term isothermal oxidation resistance at $704^{\circ} \mathrm{C}$ in air, the scale thickness only varying from 5 to $15 \mu \mathrm{m}$. The scales formed on the engineering $\gamma$-alloys are not identical and extremely complex, in particular with regards to the phases formed at the metal/scale interface. To some extent these results are at odds with generalizations made for protective behavior at higher temperatures. That is, very good behavior is observed here for $704^{\circ} \mathrm{C}$ oxidation of the engineering alloys, which do exhibit a nitride interlayer but not the brittle oxygen- and Ti-enriched, Al-depleted Z/X phase interlayer reported during oxidation above $900^{\circ} \mathrm{C}$. While at high temperature, it appears that continuous alumina scales occur primarily when the $\mathrm{Z} / \mathrm{X}$ phase is formed and the nitride layer and $\alpha_{2}-\mathrm{Ti}_{3} \mathrm{Al}$ layers are absent [27]. Much of the environmental concern for the TiAl engineering alloys stems from an embrittlement perspective - most do not form excessive scales, but may have compromised mechanical properties if a brittle surface layer forms. It is not yet clear whether the $Z / X$, nitride, or oxygen-saturated $\alpha_{2}-\mathrm{Ti}_{3} \mathrm{Al}$ phases are equally problematic.

\section{Acknowlegments}

Appreciation is expressed to J. W. Smith and T. R. McCue for dedicated and excellent microscopy work. The long-term oxidation study efforts of the engineering $\gamma$-alloys at NASA Glenn was initiated by Bill Brindley, with whom many useful discussions on the oxidation and embrittlement mechanisms in Ti-base alloys are gratefully acknowledged.

\section{References}

1. P.A. Bartolotta and D. L. Krause, NASA/TM-1999-209071, 1999.

2. H. Clemens, H. Kestler, Adv. Eng. Mater. 2 (9), 551 (2000).

3. D. Eylon, M. M. Keller and P. E. Jones, Intermetallics 6 (7-8), 703 (1998).

4. T. Noda, ibid., 709 (1998).

5. I.E. Locci, M.P. Brady, R.A. Mackay and J.W. Smith, Scripta Mat. 37 (6), 761 (1997).

6. M.P. Brady, W.J. Brindley, J.L. Smialek, I.E. Locci, JOM 48 (11), 46 (1996).

7. N.S. Jacobson, M. P. Brady, and G. M. Mehrotra, Oxidation of Metals 52, 537 (1999).

8. V.A.C. Haanappel et al., Oxidation of Metals 48, 263 (1997).

9. M. Nombela, V. Kolarik, M.Gross, H. Fietzek, and N. Eisenreich, Matl. High Temp. 17, 49 (2000).

10. A. Rahmel, W.J. Quadakkers, and M. Schutze, Materials and Corrosion 46, 271 (1995).

11. J.C. Schaeffer et al., in Gamma Titanium Aluminides, edited by Y-W Kim et al. (TMS,1995) p. 71.

12. J.M. Rakowski et al., Scr. Metall. Mater. 33, 997 (1995).

13. M. Yoshihara, K. Miura and Y-W Kim, ibid ref. 11, p.93.

14. F. Dettenwanger et al., Matls \& Corrosion 48(1), 23 (1996).

15. R.W. Beye and R. Gronsky, Acta Metall. Mater. 42 (4) 1373 (1994).

16. C.Lang and M.Schutze, Mater.Corros. 48, 13 (1997).

17. W.J. Quadakkers, N. Zheng, A. Gil, E. Wallura, H. Hoven, High Temp. Corr. Prot. Mat. 4, 187 (1997).

18. E.H. Copland, B. Gleeson, D.J. Young, Acta Mater. 47(10), 2937 (1999).

19. W.B. Retallick, M.P. Brady, D.L. Humphrey, Intermetallics 6, 335 (1998).

20. P. Perez, J.A. Jimenez, G. Frommeyer, and P. Adv. Matl. Sc. Eng. A 284, 138 (2000).

21. J. Magnan et al., Met. and Mat. Trans. A 30, 19 (1999).

22. V.A.C. Haanappel et al., Mat. High Temp. 14(1), 19 (1997).

23. J. Doychak, S. V. Raj, I.E. Locci, M. Hebsur, NASA CP-10082, 18 (1991).

24. M.P. Brady, E.D. Verink, Jr., J.W. Smith, Oxidation of Metals 51 (5-6), 539 (1999).

25. Y. Shida, and H. Anada, Oxidation of Metals 45 (1-2), 197 (1996).

26. J.D. Sunderkotter et al., Intermetallics 5, 525 (1997).

27. V. Shemet et al., Oxidation of Metals 54 (3-4), 211 (2000). 

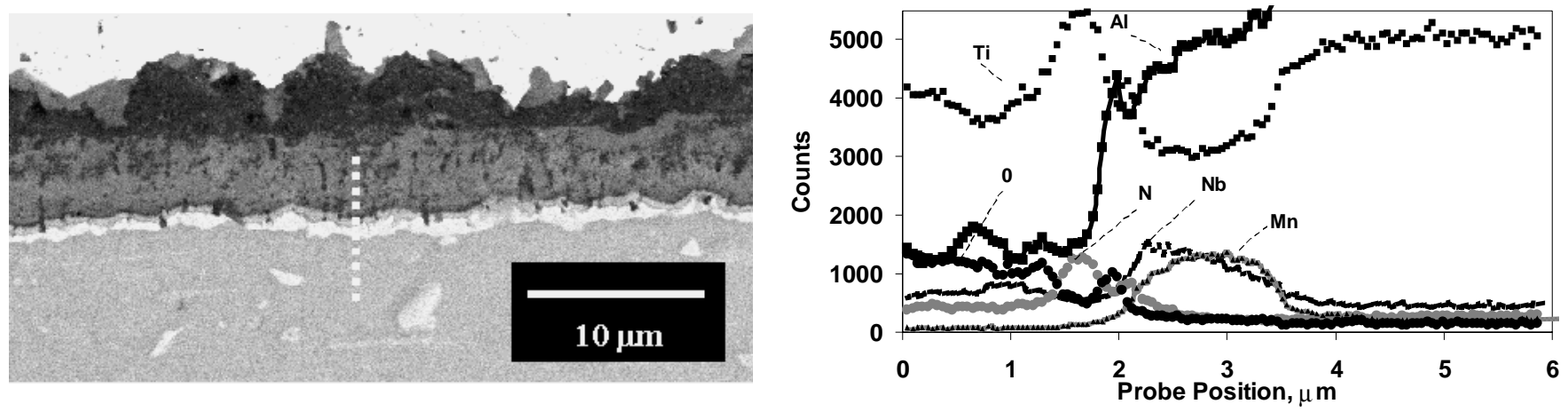

Figure 4. Typical microstructure, and FE-SEM elemental linescans observed in a XD-TiAl alloy after exposure to $704^{\circ} \mathrm{C}$ for $7000 \mathrm{hr}$ in air.
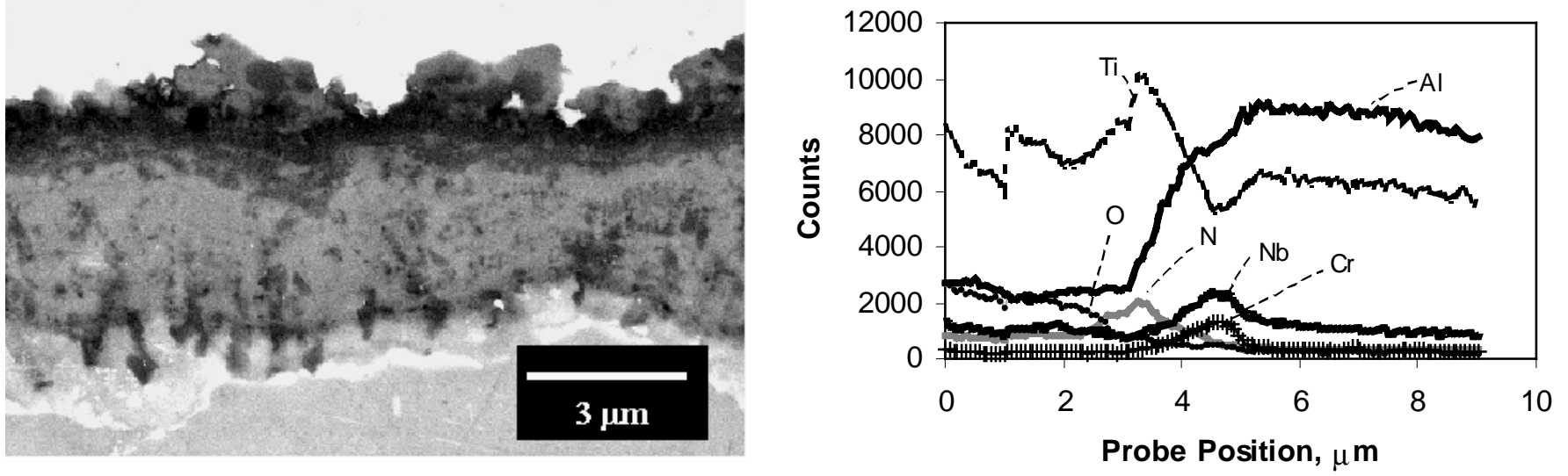

Figure 5. Typical microstructure, and $\mathrm{FE}$-SEM elemental linescans observed in alloy $\mathrm{K} 5$ after exposure to $704^{\circ} \mathrm{C}$ for $7000 \mathrm{hr}$ in air.

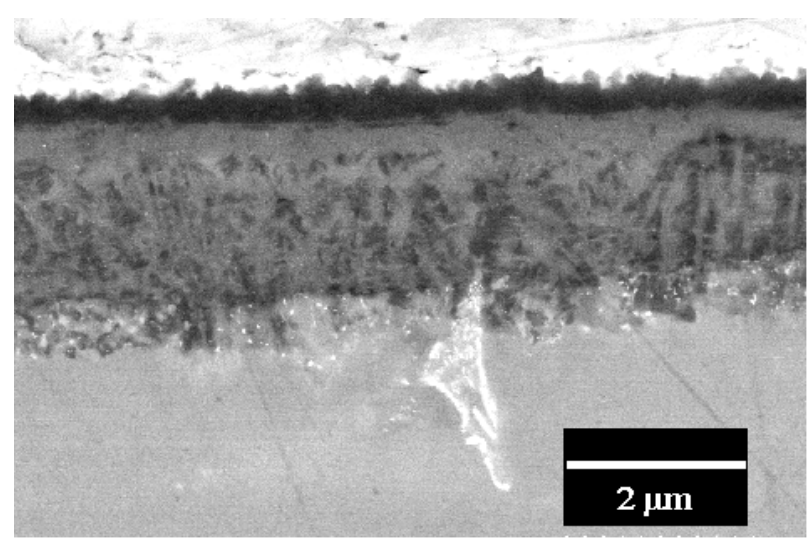

Figure 6. Typical microstructure observed in alloy 7 after exposure to $704^{\circ} \mathrm{C}$.

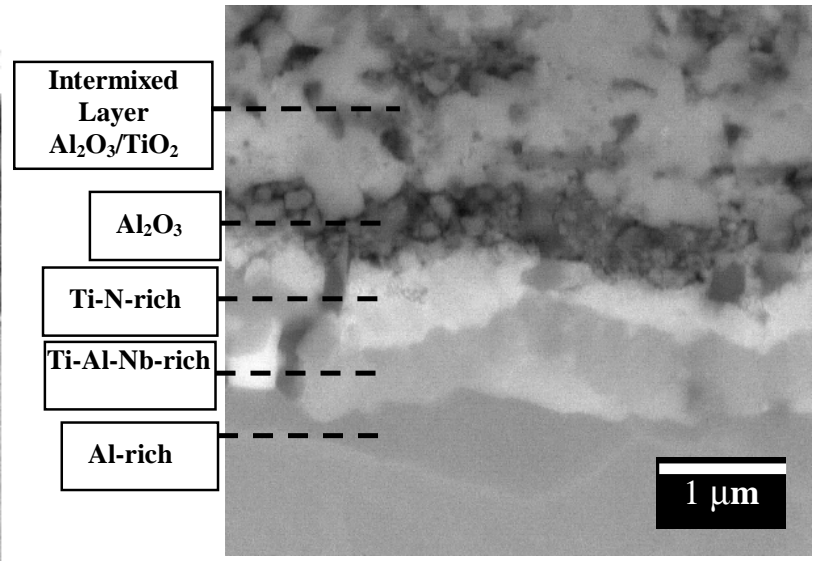

Figure 7. Typical microstructure observed at the metal/scale interface in TiAl-2Cr-2Nb after $800^{\circ} \mathrm{C}$.

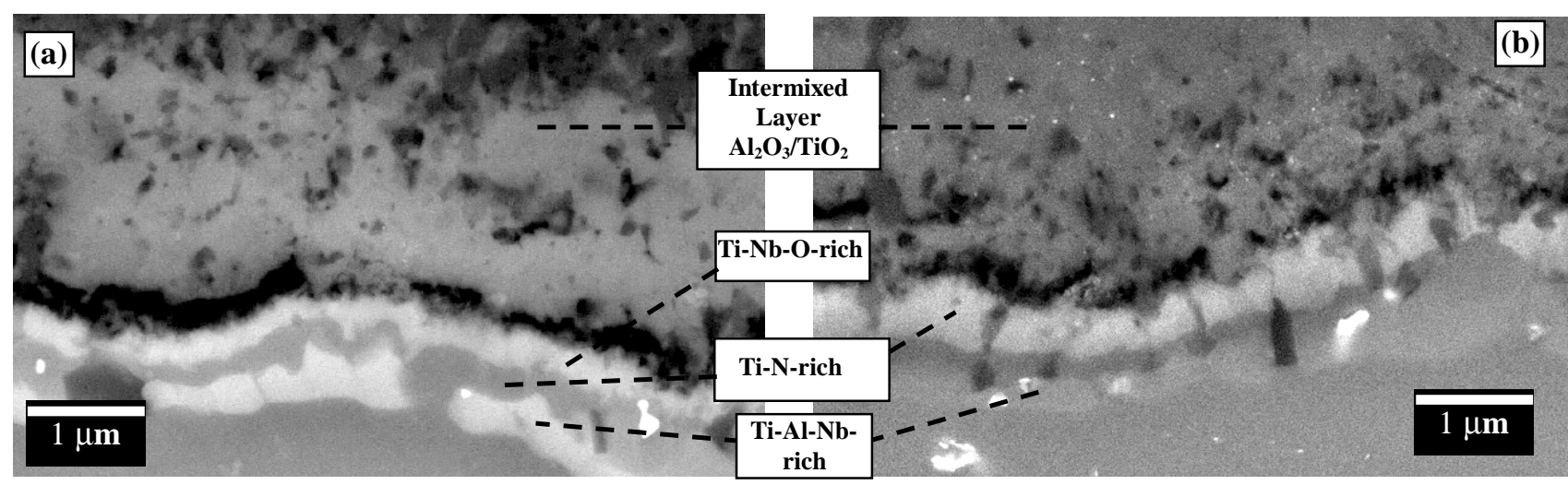

Figure 8. Typical microstructure observed at the metal/scale interface for (a) Alloy K5, (b) Alloy 7 after $800^{\circ} \mathrm{C}-1000 \mathrm{~h}$. 